\title{
Current in lighting wire grounded in each tower determination under short circuit to tower or short circuit to earth escape tower
}

\author{
Kirill Zimin ${ }^{1}$, Nina Rubtsova ${ }^{2}$, Andrey Tokarskiy ${ }^{1}$ \\ ${ }^{1}$ Joint-Stock Company "Research and Development Center of the Federal Grid Company of Unified Energy System", Kashirskoe shosse, \\ 22, bld.3, Moscow, Russia \\ ${ }^{2}$ Federal State Budgetary Scientific Institution “Izmerov Research Institute of Occupational Health”, prospect Budennogo,31, \\ Moscow, Russia
}

\begin{abstract}
The algorithms for short circuit (SC) currents as well as induced in grounded in each tower lighting wire (LW) currents are presented for the case of SC to overhead transmission line $(\mathrm{OTL})$ tower and to the ground passing the tower.
\end{abstract}

\section{Introduction}

Overhead transmission lines (OTL) are equipeed by lighting wires ontaining fiber optical communication channels (FOLW). FOLW technically are grounded in each OTL tower. OTL damaged phase current magnetic field (MF) as well as short circuit (SC) current in FOLW under SC is created the current, and this current value should not exceed the value permissible by thermal stability. In the report of this workshop 2018 [1,2] Double-circuit $220 \mathrm{kV}$ OTL $46.956 \mathrm{~km}$ length without transpositions in tower Itph220-2+5 brand is discussed (Figure 1). There are determined self- and mutualinductive resistance, earth resistance as well as

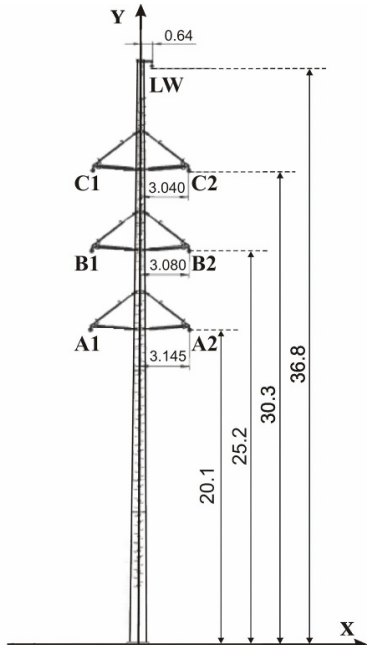

Fig. 1. $220 \mathrm{kV}$ double-circuit OTL on intermediate tower.

brands LW: FOLW-c-1-24(G.652)-18,7/93, FOLW-c-116(G.652)-14,7/61, FOLW-c-1-24(G.652)-13,1/54 and FOLW-ц-1-48(G.652)-12/94. Maximal current value was induced in 6th span under SC at $5 \mathrm{~km}$ distance from substation 2 for all FOLW (for FOLW-...-18.7/93 $\mathrm{I}_{\mathrm{Wmax}}=$ $\mathrm{I}_{\mathrm{W} 6}=5.48 \mathrm{kA}$ ). There are determined the currents induced in FOLW for simultanious $\mathrm{C} 1$ and $\mathrm{C} 2$ phases $\mathrm{SC}$ to the ground at $5 \mathrm{~km}$ distanse from substation 2 unlikely case. This case for FOLW $-\ldots-18.7 / 93 \mathrm{I}_{\mathrm{W} \max }=\mathrm{I}_{\mathrm{W} 6}=6.296 \mathrm{kA}$. In [2] there was discussed the case of $220 \mathrm{kV}$ OTL C2 phase (connected to substation 1 and substation 2 and operation without power transmission) $\mathrm{SC}$ to the ground at $5 \mathrm{~km}$ distance from substation 2, and FOLW-...-18.7/93 $\mathrm{I}_{\mathrm{Wmax}}=\mathrm{I}_{\mathrm{W} 6}=5.152 \mathrm{kA}$. SC current and induced in LW current simultaneous determination were carried out for $220 \mathrm{kV}$ OTL idling case at substation 1 (S1) side and C2 phase $\mathrm{SC}$ to the ground at $5 \mathrm{~km}$ distance from substation 2 [1,2] (Figure 2).

Current simultaneous determination method allows taking into account the current in LW affect to SC current as well as SC current flowing into LW. Under case of simultaneous calculation method current greatest value in LW is accounts for first span from substation 2 (S2), and for $220 \mathrm{kV}$ OTL FOLW-...-18.7/93 $\mathrm{I}_{\mathrm{Wmax}}=\mathrm{I}_{\mathrm{W} 1}$ $=6.876 \mathrm{kA}$.

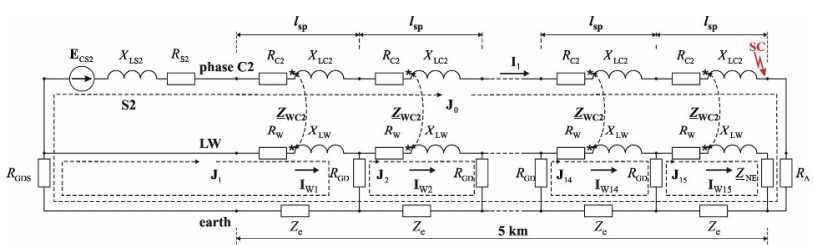

Fig. 2. The sheme of simultanious determination of $\mathrm{C} 2$ phase $\mathrm{SC}$ current to the ground, and currents induced in LW.

\section{Current in LW depend on distance from $\mathrm{C} 2$ phase operating in idle regime at $\mathrm{S} 1$ side $\mathrm{SC}$ to the ground place}

For FOLW testing brands let's make a simultaneous determination of SC current and currents in wires under 
$\mathrm{C} 2$ phase $\mathrm{SC}$ to the ground at the ends of span. The number (No.) of SC span: $1 \div 5,8,10 \div 15$ and 18 . Maximal current module value in FOLW for all calculated cases were in first from S2 span, i.e. current $\mathrm{I}_{\mathrm{W} 1}$ has the maximal value.

Figure 3 shows the histogram of current module value of $220 \mathrm{kV}$ OTL with FOLW -...-18.7/93, figure 4 - with FOLW-...-14.7/61 and FOLW-...-13.1/54, and figure 5 - with FOLW-...-12/94.

$\mathrm{I}_{\mathrm{W} 1}$ Greatest current values for:

FOLW-...-18.7/93 under SC span No.=12, $\mathrm{I}_{\mathrm{LW1}}=7.42 \mathrm{kA}$; FOLW-...-14.7/61 under SC span No. $=11, \mathrm{I}_{\mathrm{LWl}}=6.86 \mathrm{kA}$; FOLW-...-13.1/54 under SC span No. $=10, \mathrm{I}_{\mathrm{LW1}}=6.42 \mathrm{kA}$; FOLW-...-12.0/94 under SC span No. $=8, \mathrm{I}_{\mathrm{LW1}}=4.64$ кA.

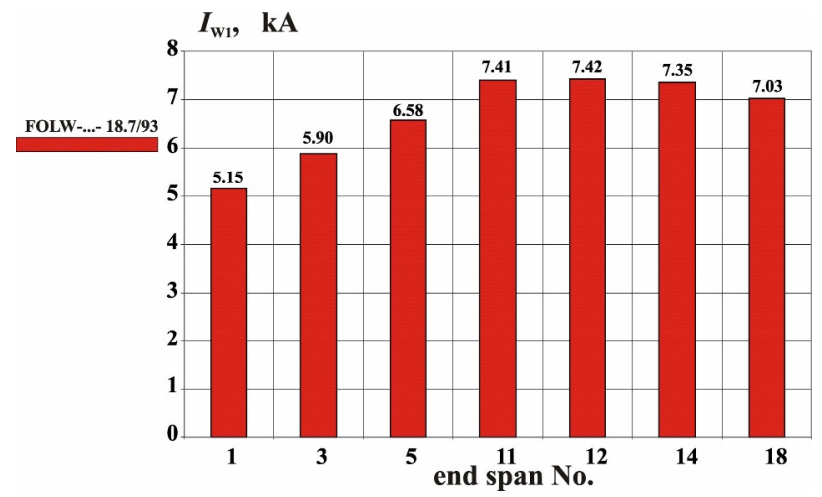

Fig. 3. The histograms of $\mathrm{I}_{\mathrm{LW} 1}$ currents for $220 \mathrm{kV}$ OTL with FOLW-...-18.7/93 under $\mathrm{C} 2$ phase $\mathrm{SC}$ to the ground at the end of span number: 1, 3, 5, 11, 12, 14 and 18

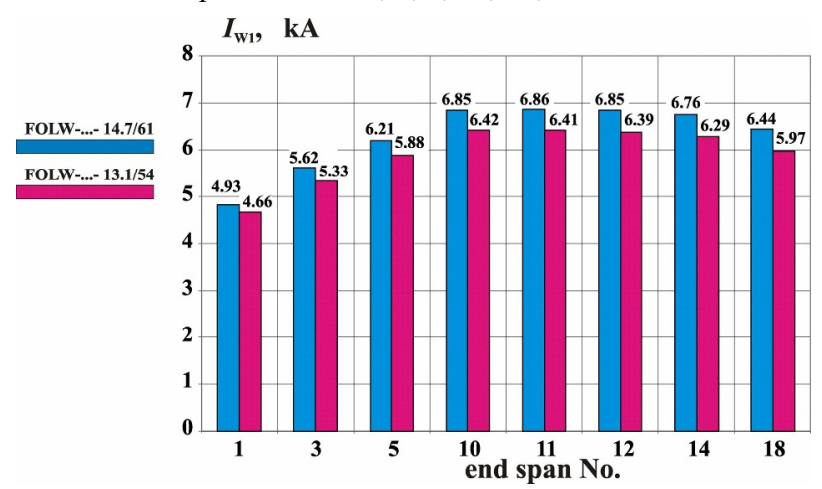

Fig. 4. The histograms of $I_{L W 1}$ currents for $220 \mathrm{kV}$ OTL with FOLW-...-14.7/61 and FOLW-...-13.1/54 under C2 phase SC to the ground at the end of span number: $1,3,5,10,11,12,14$ and 18

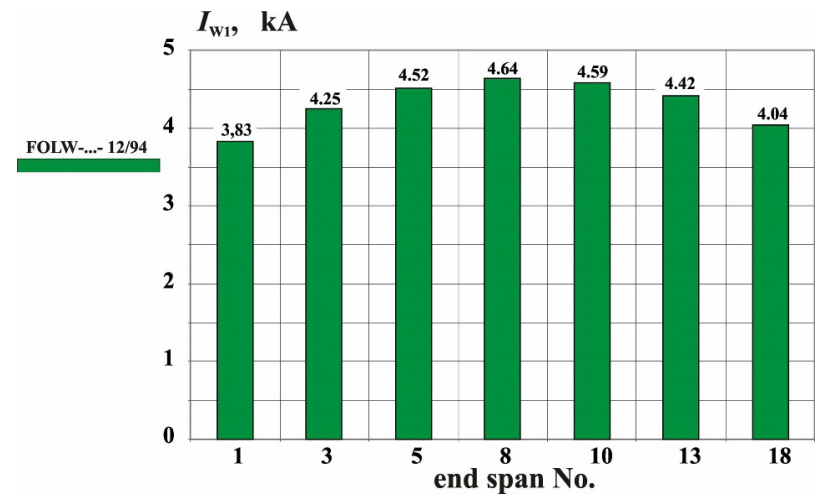

Fig. 5. The histograms of $\mathrm{I}_{\mathrm{LW} 1}$ currents for $220 \mathrm{kV}$ OTL with FOLW-...-12/94 under $\mathrm{C} 2$ phase $\mathrm{SC}$ to the ground at the end of span numbers: $1,3,5,8,10,13$ и 18

\section{Current in LW depending on distance to $S 2$ from $C 1$ and $C 2$ phases $220 \mathrm{kV}$ OTL operating in idle mode at $\mathrm{S} 1$ side SC to the ground place}

Let's calculate the currents of simultaneous $\mathrm{C} 1$ and $\mathrm{C} 2$ phases SC to the ground as well as currents in LW. SC is at the end of 15 th span from $220 \mathrm{kV} \mathrm{S} 2$ operating in idle mode. The sheme of calculation is shown in figure 6.

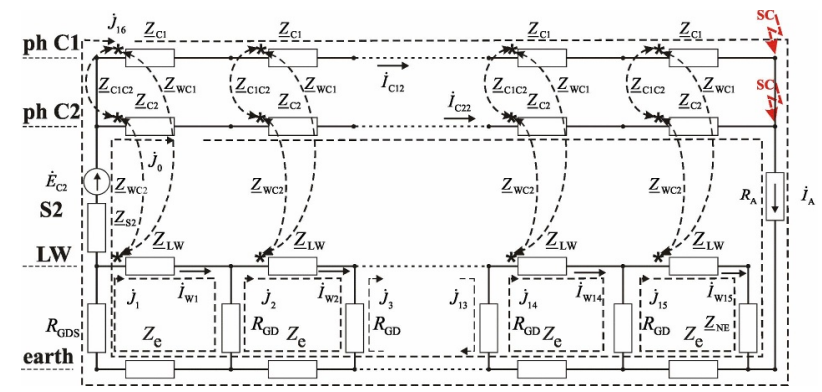

Fig. 6. The scheme of $\mathrm{C} 1$ and $\mathrm{C} 2$ phases simultanious $\mathrm{SC}$ to the ground at the end of 15th span from S2.

Let's analyse $220 \mathrm{kV}$ OTL with FOLW-...-18.7/93. Then for figure 6 sheme: $\underline{Z}_{\mathrm{C} 1}=R_{\mathrm{C} 1}+\mathrm{j} X_{\mathrm{LC} 1}=\underline{Z}_{\mathrm{C} 2}=R_{\mathrm{C} 2}+$ $\mathrm{j} X_{\mathrm{LC} 2}=0.02433+\mathrm{j} 0.23388 \mathrm{Ohm} ; \underline{Z}_{\mathrm{LW}}=R_{\mathrm{W}}+\mathrm{j} X_{\mathrm{LW}}=$ $0.0667+\mathrm{j} 0.2422 \mathrm{Ohm} ; Z_{\mathrm{e}}=0.01533 \mathrm{Ohm} ; \underline{Z}_{\mathrm{WC} 1}=$ $0.0154+\mathrm{j} 0.100 \mathrm{Ohm} ; \quad \underline{\mathrm{Z}}_{\mathrm{WC} 2}=0.015+\mathrm{j} 0.101 \mathrm{Ohm} ;$ $\underline{Z}_{\mathrm{C} 1 \mathrm{C} 2}=0.0155+\mathrm{j} 0.1167 \mathrm{Ohm} ; \quad \underline{Z}_{\mathrm{S} 2}=R_{\mathrm{S} 2}+\mathrm{j} X_{\mathrm{LS} 2}=$ $0.841+\mathrm{j} 5.796 \mathrm{Ohm} ; \underline{Z}_{\mathrm{NE}}=1.257+\mathrm{j} 0.816 \mathrm{Ohm} ; R_{\mathrm{GDS}}=$ $0.5 \mathrm{Ohm} ; R_{\mathrm{GD}}=10 \mathrm{Ohm} ; R_{\mathrm{A}}=0.42 \mathrm{Ohm} ; \boldsymbol{E}_{\mathrm{C} 2}=$ $127017 \angle 120^{\circ} \mathrm{B}$.

System of equations by the method of contour currents:

$$
\begin{aligned}
& \dot{J}_{0}\left(\underline{Z}_{\mathrm{S} 2}+15 \underline{Z}_{\mathrm{C} 2}+15 Z_{\mathrm{e}}+R_{\mathrm{A}}+R_{\mathrm{GDS}}\right)+\dot{J}_{1}\left(R_{\mathrm{GDS}}+Z_{\mathrm{e}}+\underline{Z}_{\mathrm{WC} 2}\right)+\dot{J}_{2}\left(Z_{\mathrm{e}}+\underline{Z}_{\mathrm{WC} 2}\right)+\ldots \\
& \ldots+\dot{J}_{15}\left(Z_{\mathrm{e}}+\underline{Z}_{\mathrm{WC} 2}\right)+\dot{J}_{16}\left(\underline{Z}_{\mathrm{S} 2}+R_{\mathrm{A}}+15 Z_{\mathrm{e}}+R_{\mathrm{GDS}}+15 \underline{Z}_{\mathrm{ClC} 2}\right)=\dot{E}_{\mathrm{C} 2} ; \\
& \dot{J}_{0}\left(R_{\mathrm{GDS}}+Z_{\mathrm{e}}+\underline{Z}_{\mathrm{WC}}\right)+\dot{J}_{1}\left(\underline{Z}_{\mathrm{LW}}+R_{\mathrm{GD}}+Z_{\mathrm{e}}+R_{\mathrm{GDS}}\right)-\dot{J}_{2} R_{\mathrm{GD}}+ \\
& +\dot{J}_{16}\left(R_{\mathrm{GDS}}+Z_{\mathrm{e}}+\underline{Z}_{\mathrm{WCl}}\right)=0 \\
& \dot{J}_{0}\left(Z_{\mathrm{e}}+\underline{Z}_{\mathrm{WC} 2}\right)-\dot{J}_{1} R_{\mathrm{GD}}+\dot{J}_{2}\left(\underline{Z}_{\mathrm{LW}}+2 R_{\mathrm{GD}}+Z_{\mathrm{e}}\right)-\dot{J}_{3} R_{\mathrm{GD}}+\dot{J}_{16}\left(Z_{\mathrm{e}}+\underline{Z}_{\mathrm{WC1}}\right)=0 ; \\
& \dot{J}_{0}\left(Z_{\mathrm{e}}+\underline{Z}_{\mathrm{WC}}\right)-\dot{J}_{13} R_{\mathrm{GD}}+\dot{J}_{14}\left(\underline{Z}_{\mathrm{LW}}+2 R_{\mathrm{GD}}+Z_{\mathrm{e}}\right)-\dot{J}_{15} R_{\mathrm{GD}}+\dot{J}_{16}\left(Z_{\mathrm{e}}+\underline{Z}_{\mathrm{WC1}}\right)=0 \text {; } \\
& \dot{J}_{0}\left(Z_{\mathrm{e}}+\underline{Z}_{\mathrm{WC} 2}\right)-\dot{J}_{14} R_{\mathrm{GD}}+\dot{J}_{15}\left(\underline{Z}_{\mathrm{LW}}+Z_{\mathrm{NE}}+Z_{\mathrm{e}}+R_{\mathrm{GD}}\right)+\dot{J}_{16}\left(Z_{\mathrm{e}}+\underline{Z}_{\mathrm{WCI}}\right)=0 ; \\
& \dot{J}_{0}\left(\underline{Z}_{\mathrm{S} 2}+15 \underline{Z}_{\mathrm{Cl}}+15 Z_{\mathrm{e}}+R_{\mathrm{A}}+R_{\mathrm{GDS}}\right)+\dot{J}_{1}\left(R_{\mathrm{GDS}}+Z_{\mathrm{e}}+\underline{Z}_{\mathrm{WC} 2}\right)+\dot{J}_{2}\left(Z_{\mathrm{e}}+\underline{Z}_{\mathrm{WC} 1}\right)+ \\
& \ldots+\dot{J}_{14}\left(Z_{\mathrm{e}}+\underline{Z}_{\mathrm{WCl}}\right)+\dot{J}_{15}\left(Z_{\mathrm{e}}+\underline{Z}_{\mathrm{WCl}}\right)+ \\
& +\dot{J}_{16}\left(\underline{Z}_{\mathrm{S} 2}+15 \underline{Z}_{\mathrm{C} 1}+15 Z_{\mathrm{e}}+R_{\mathrm{A}}+R_{\mathrm{GDS}}\right)=\dot{E}_{\mathrm{C} 2} \text {. }
\end{aligned}
$$

Solving equations system and considering that $\boldsymbol{I}_{\mathrm{C} 12}=$ $\boldsymbol{J}_{16}, \boldsymbol{I}_{\mathrm{C} 12}=\boldsymbol{J}_{0}, \boldsymbol{I}_{\mathrm{LW} 1}=\boldsymbol{J}_{1}, \boldsymbol{I}_{\mathrm{LW} 15}=\boldsymbol{J}_{15}$, and $\boldsymbol{I}_{\mathrm{A}}=\boldsymbol{J}_{0}+\boldsymbol{J}_{16}$, will obtain:

$\boldsymbol{I}_{\mathrm{C} 12}=7.868 \angle 43.5^{\circ} \mathrm{kA} ; \quad \boldsymbol{I}_{\mathrm{C} 22}=7.822 \angle 43.3^{\circ} \mathrm{kA}$; $\boldsymbol{I}_{\mathrm{A}}=15.691 \angle 43.4^{\circ} \mathrm{kA}$;

$\boldsymbol{I}_{\mathrm{LW} 1}=8.055 \angle-138.3^{\circ} \mathrm{kA} ; \boldsymbol{I}_{\mathrm{LW} 2}=7.696 \angle-138.2^{\circ} \mathrm{kA}$; $\boldsymbol{I}_{\mathrm{LW} 3}=7.357 \angle-137.8^{\circ} \mathrm{kA} ; \ldots ; \boldsymbol{I}_{\mathrm{LW13}}=4.160 \angle-133.0^{\circ} \mathrm{kA}$; $\boldsymbol{I}_{\mathrm{LW} 14}=3.767 \angle-134.5^{\circ} \mathrm{kA} ; \boldsymbol{I}_{\mathrm{LW} 16}=3.358 \angle-137.5^{\circ} \mathrm{kA}$.

Ток $I_{\mathrm{LW} 1}$ current has maximal value.

There were carried out simultanious SC current determination as well as currents in LWs under $\mathrm{C} 1$ and $\mathrm{C} 2 \mathrm{SC}$ to the ground at the end of span (all analised FOLW brands). No. of span: 1, 3, 5, 8, 10, 11, 12, 13, 14, 18 (Figures 7, 8 and 9).

Maximal current values $\boldsymbol{I}_{\mathrm{LW} 1}$ for:

FOLW-...-18.7/93 under SC span No. $=13, I_{\mathrm{LW} 1}=8.09 \mathrm{kA}$; FOLW-...-14.7/61 under SC span No. $=12, I_{\mathrm{LW} 1}=7.45 \mathrm{kA}$; FOLW-...-13.1/54 under SC $\operatorname{span}$ No. $=12, I_{\mathrm{LW} 1}=6.96 \mathrm{kA}$; 
FOLW-...-12.0/94 under SC span No. $=8, I_{\text {LW } 1}=4.93 \mathrm{kA}$.

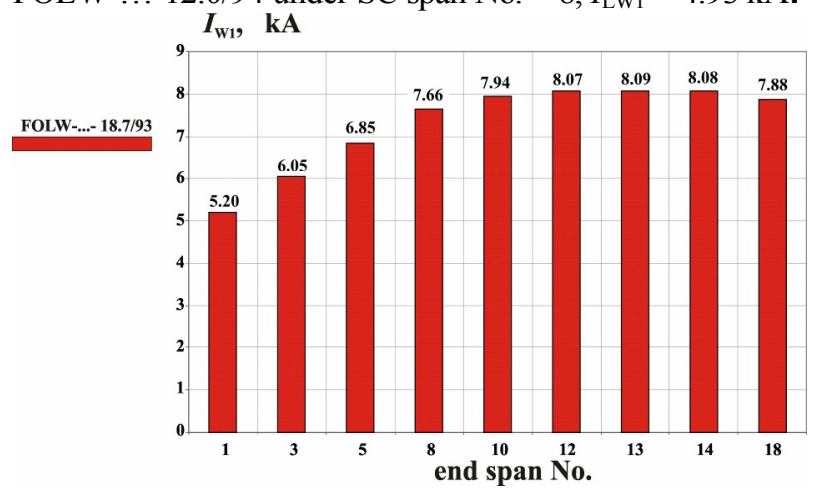

Fig. 7. The histograms of $I_{L w 1}$ currents for $220 \mathrm{kV}$ OTL with FOLW-...-18.7/93 under $\mathrm{C} 1$ and $\mathrm{C} 2$ phase $\mathrm{SC}$ to the ground at the end of span number: $1,3,5,8,10,12,13,14$ и 18

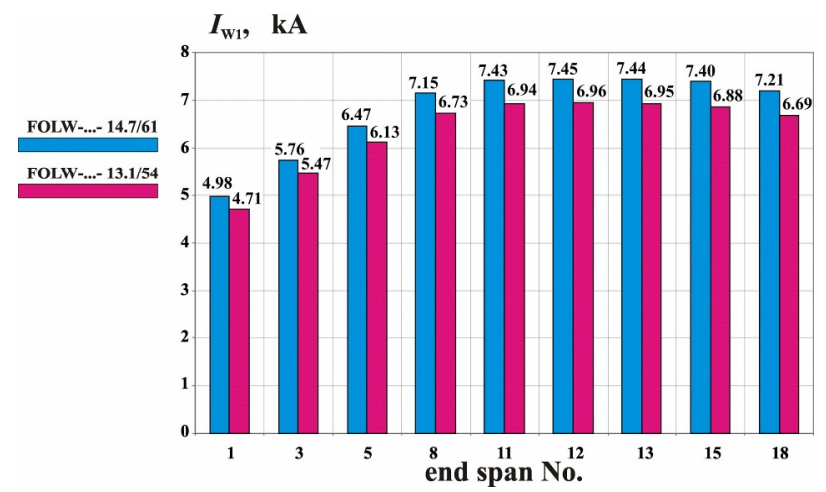

Fig. 8. The histograms of $\mathrm{I}_{\mathrm{LW} 1}$ currents for $220 \mathrm{kV}$ OTL with FOLW -...-14.7/61 and FOLW-...-13.1/54 under C1 and C2 phase SC to the ground at the end of span number: $1,3,5,8$, $11,12,13,15$ и 18

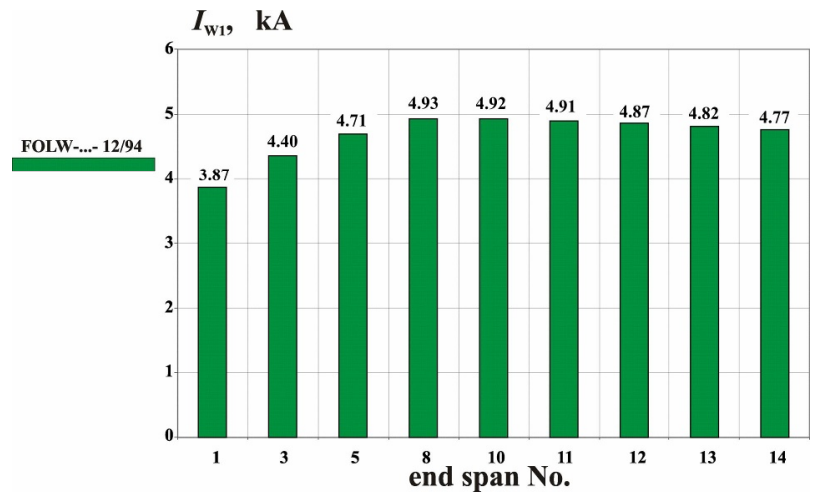

Fig. 9. The histograms of $\mathrm{I}_{\mathrm{LW} 1}$ currents for $220 \mathrm{kV}$ OTL with FOLW -...-12/94 under $\mathrm{C} 1$ and $\mathrm{C} 2$ phase $\mathrm{SC}$ to the ground at the end of span number: $=1,3,5,8,10,11,12,13$ и 14

\section{Current in LW depending on the distance from $220 \mathrm{kV}$ OTL (operating in in connected mode, but without power transmission) C2 phase SC to tower place to $\mathbf{S 2}$}

Currents in LW $220 \mathrm{kV}$ OTL operating in connected to both side mode but without power transmission SC current and and C2 phase SC to tower of first from S2 span current simultanious calculation will make (Figure $10)$.

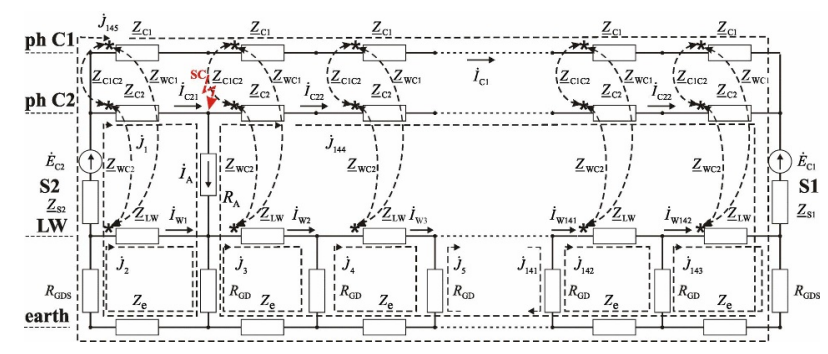

Fig. 10. The scheme of OTL $220 \mathrm{kV}$ operating in both side connection but without power transmission $\mathrm{C} 2$ phase $\mathrm{SC}$ to tower of $1^{\text {st }}$ from S2 span.

The system of equations by countur current method:

$$
\begin{aligned}
& \dot{J}_{1}\left[\underline{Z}_{\mathrm{S} 2}+\underline{Z}_{\mathrm{C} 2}+Z_{\mathrm{e}}+R_{\mathrm{A}}+R_{\mathrm{GD}}+R_{\mathrm{GDS}}\right]+ \\
& +\dot{J}_{2}\left(R_{\mathrm{GDS}}+Z_{\mathrm{e}}+R_{\mathrm{GD}}+\underline{Z}_{\mathrm{WC} 2}\right)-\dot{J}_{3} R_{\mathrm{GD}}+0+\ldots+0+ \\
& +0-\dot{J}_{144}\left(R_{\mathrm{GD}}+R_{\mathrm{A}}\right)+\dot{J}_{145}\left(\underline{Z}_{\mathrm{S} 2}+R_{\mathrm{GDS}}+Z_{\mathrm{e}}+\underline{Z}_{\mathrm{ClC} 2}\right)=\dot{E}_{\mathrm{C} 2} ; \\
& \dot{J}_{1}\left(R_{\mathrm{GDS}}+Z_{\mathrm{e}}+R_{\mathrm{GD}}+\underline{Z}_{\mathrm{WC} 2}\right)+\dot{J}_{2}\left(\underline{Z}_{\mathrm{LW}}+R_{\mathrm{GD}}+Z_{\mathrm{e}}+R_{\mathrm{GDS}}\right)-\dot{J}_{3} R_{\mathrm{GD}}+0+\ldots+0- \\
& -\dot{J}_{144} R_{\mathrm{GD}}+\dot{J}_{145}\left(R_{\mathrm{GDS}}+Z_{\mathrm{e}}+\underline{Z}_{\mathrm{WCI}}\right)=0 \text {; } \\
& -\dot{J}_{1} R_{\mathrm{GD}}-\dot{J}_{2} R_{\mathrm{GD}}+\dot{J}_{3}\left(\underline{Z}_{\mathrm{LW}}+2 R_{\mathrm{GD}}+Z_{\mathrm{e}}\right)-\dot{J}_{4} R_{\mathrm{GD}}+0+\ldots+0+ \\
& +0+\dot{J}_{144}\left(Z_{\mathrm{e}}+R_{\mathrm{GD}}+\underline{Z}_{\mathrm{WC} 2}\right)+\dot{J}_{145}\left(Z_{\mathrm{e}}+\underline{Z}_{\mathrm{WC1}}\right)=0 \text {; } \\
& 0+\ldots+0-\dot{J}_{142} R_{\mathrm{GD}}+\dot{J}_{143}\left(\underline{Z}_{\mathrm{LW}}+R_{\mathrm{GDS}}+R_{\mathrm{GD}}+Z_{\mathrm{e}}\right)+ \\
& +\dot{J}_{144}\left(R_{\mathrm{GDS}}+Z_{\mathrm{e}}+\underline{Z}_{\mathrm{WC} 2}\right)+\dot{J}_{145}\left(R_{\mathrm{GDS}}+Z_{\mathrm{e}}+\underline{Z}_{\mathrm{WC} 1}\right)=0 ; \\
& -\dot{J}_{1}\left(R_{3 \mathrm{Y}}+R_{\mathrm{A}}\right)-\dot{J}_{2} R_{\mathrm{GD}}+\dot{J}_{3}\left(R_{\mathrm{GD}}+Z_{\mathrm{e}}+\underline{Z}_{\mathrm{WC}}\right)+\dot{J}_{4}\left(Z_{\mathrm{e}}+\underline{Z}_{\mathrm{WC} 2}\right)+ \\
& +\dot{J}_{5}\left(Z_{\mathrm{e}}+\underline{Z}_{\mathrm{WC} 2}\right)+\ldots+\dot{J}_{141}\left(Z_{\mathrm{e}}+\underline{Z}_{\mathrm{WC} 2}\right)+\dot{J}_{142}\left(Z_{\mathrm{e}}+\underline{Z}_{\mathrm{WC2}}\right)+ \\
& +\dot{J}_{143}\left(R_{\mathrm{GDS}}+Z_{\mathrm{e}}+\underline{Z}_{\mathrm{WC} 2}\right)+\dot{J}_{144}\left[\underline{Z}_{\mathrm{S} 1}+141\left(\underline{Z}_{\mathrm{C} 2}+Z_{\mathrm{e}}\right)+R_{\mathrm{A}}+R_{\mathrm{GD}}+R_{\mathrm{GDS}}\right]+ \\
& +\dot{J}_{145}\left(\underline{Z}_{\mathrm{S} 1}+R_{\mathrm{GDS}}+141 Z_{\mathrm{e}}+141 \underline{Z}_{\mathrm{C} 1 \mathrm{C} 2}\right)=-\dot{E}_{\mathrm{C} 1} \text {; } \\
& \dot{J}_{1}\left(\underline{Z}_{\mathrm{S} 2}+R_{\mathrm{GDS}}+Z_{\mathrm{e}}+\underline{Z}_{\mathrm{CIC}}\right)+\dot{J}_{2}\left(R_{\mathrm{GDS}}+Z_{\mathrm{e}}+\underline{Z}_{\mathrm{WC1}}\right)+\dot{J}_{3}\left(Z_{\mathrm{e}}+\underline{Z}_{\mathrm{WC1}}\right)+ \\
& +\dot{J}_{4}\left(Z_{\mathrm{e}}+\underline{Z}_{\mathrm{WC1}}\right)+\ldots+\dot{J}_{141}\left(Z_{\mathrm{e}}+\underline{Z}_{\mathrm{WC1}}\right)+\dot{J}_{142}\left(Z_{\mathrm{e}}+\underline{Z}_{\mathrm{WC1}}\right)+ \\
& +\dot{J}_{143}\left(R_{\mathrm{GDS}}+Z_{\mathrm{e}}+\underline{Z}_{\mathrm{WC} 1}\right)+\dot{J}_{144}\left(\underline{Z}_{\mathrm{S} 1}+R_{\mathrm{GDS}}+141 Z_{\mathrm{e}}+141 \underline{Z}_{\mathrm{CIC} 2}\right)+ \\
& +\dot{J}_{145}\left[\underline{Z}_{\mathrm{S} 2}+\underline{Z}_{\mathrm{S} 1}+142\left(\underline{Z}_{\mathrm{C} 1}+Z_{\mathrm{e}}\right)+2 R_{\mathrm{GDS}}\right]=\dot{E}_{\mathrm{C} 2}-\dot{E}_{\mathrm{C} 1} \text {. }
\end{aligned}
$$

The solving of eguation system give the values of SC current, currents in LW as well as in $\mathrm{C} 1$ and $\mathrm{C} 2$ phases. Figure 11 shows the hisogramms of current modules for $220 \mathrm{kV}$ OTL with FOLW-..-18.7/93 $\left(\underline{Z}_{\mathrm{LW}}=0.066+\right.$ j0.240 Ohm) and with FOLW-...-12/94 ( $\underline{\mathrm{Z}}_{\mathrm{LW}}=0.368+$ j0.249 Ohm), and in figure 12 - with FOLW-...-14.7/61 $\left(\underline{Z}_{\mathrm{LW}}=0.109+\mathrm{j} 0.245 \mathrm{Ohm}\right)$ and with FOLW-...-13.1/54 $\left(\underline{Z}_{\mathrm{LW}}=0.146+\mathrm{j} 0.427 \mathrm{Ohm}\right)$.

Under $\mathrm{C} 2$ phase $\mathrm{SC}$ to $1^{\text {st }}$ span tower arc current were: for FOLW-...-18.7/93 $\boldsymbol{I}_{\mathrm{A}}=24.74 \angle 43.3^{\circ} \mathrm{kA}$, for FOLW$\ldots-12 / 94 \boldsymbol{I}_{\mathrm{A}}=24.01 \angle 43.0^{\circ} \mathrm{kA}$, for FOLW-...-14.7/61 $\boldsymbol{I}_{\mathrm{A}}$ $=24.65 \angle 44.0^{\circ} \mathrm{kA}$, and for FOLW-..-13.1/54 $\boldsymbol{I}_{\mathrm{A}}=$ $24.54 \angle 44.5^{\circ} \mathrm{kA}$.

Figure 13 shows the histogram of currents under SC of C2 phase of OTL with FOLW-...-18.7/93 and with FOLW$\ldots-12 / 94$ to $5^{\text {th }}$ tower from substation 2 , and figure $14-$ to $30^{\text {th }}$ tower from substation 2 .

The distance of SC to tower place from substation 2 lead to phase current values as well as current in LW and arc current $I_{\mathrm{A}}$ dicrease. Current higher value in $\mathrm{LW}$ is achieved in the span located in the direction of the nearest from the tower on which was SC substation. In our case in the substation 2 direction. The greatest value is current $I_{\mathrm{W} 1}$ under SC to $1^{\text {st }}$ span tower.

Figure 15 shows the histograms of greatest current module values $I_{\mathrm{Wmax}}$ in $\mathrm{LW}$ under $\mathrm{SC}$ to tower of $1 \div 5$ th, 10th, 15th, 20th, 30th and 40th span from S2 side for FOLW-c-1-24(G.652)-18.7/93 and FOLW-c-148(G.652)-12/94. 


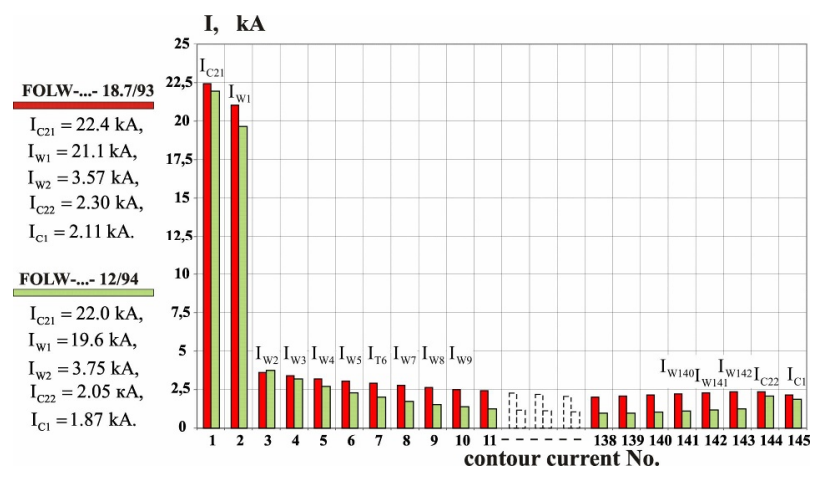

Fig. 11. Current modules under $\mathrm{SC}$ of $\mathrm{C} 2$ phase $\mathrm{SC}$ to $1^{\text {st }}$ span from S2 for FOLW-...-18.7/93 and FOLW-...-12/94.

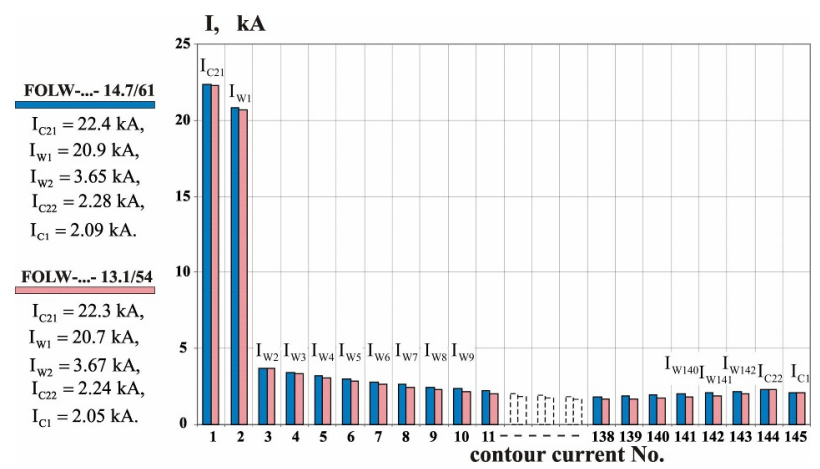

Fig. 12. Current modules under $\mathrm{SC}$ of $\mathrm{C} 2$ phase $\mathrm{SC}$ to $1^{\text {st }}$ span from S2 for FOLW-...-14.7/61 and FOLW-...-13.1/54.

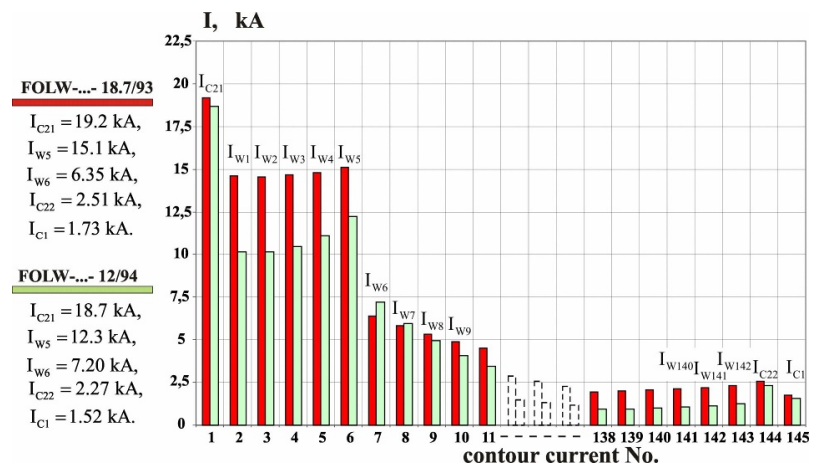

Fig. 13. Current modules under $\mathrm{SC}$ of $\mathrm{C} 2$ phase $\mathrm{SC}$ to $5^{\text {th }}$ span from $\mathrm{S} 2$ for FOLW-...-18.7/93 and FOLW-...-12/94.

When OTL is powered from $\mathrm{S} 1$ side, idle at S2 side and $\mathrm{SC}$ to $1^{\text {st }}$ from $\mathrm{S} 1$ tower $\mathrm{I}_{\mathrm{W} 1}$ current has a lower value (Fig. 16), because $\underline{Z}_{\mathrm{N} 1}=0.93+\mathrm{j} 8.46 \mathrm{Ohm}$ network resistance at $\mathrm{S} 1$ side is more network resistance $\underline{Z}_{\mathrm{N} 2}=0.84+\mathrm{j} 5.00$ $\mathrm{Ohm}$ at $\mathrm{S} 2$ side.

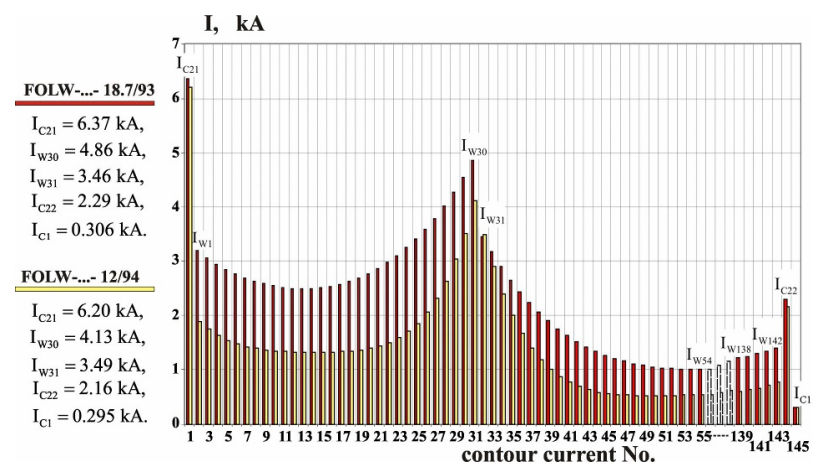

Fig. 14. Current modules under $\mathrm{SC}$ of $\mathrm{C} 2$ phase $\mathrm{SC}$ to $30^{\text {th }}$ span from S2 for FOLW-...-18.7/93 and FOLW-...-12/94.

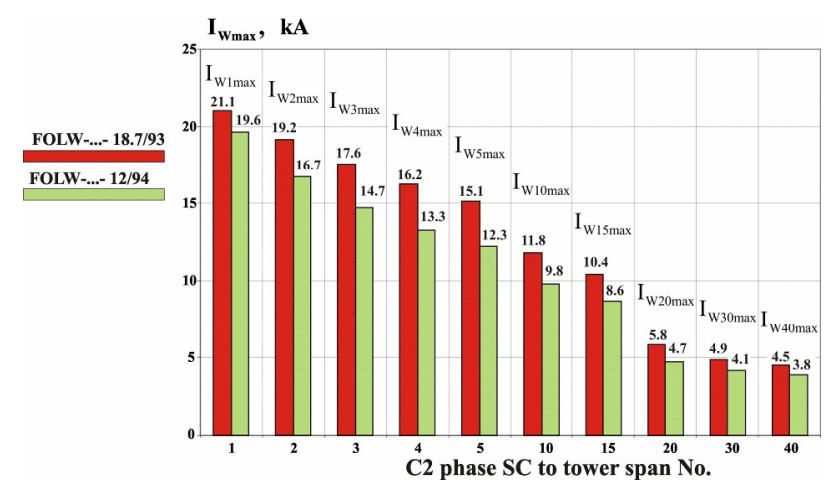

Fig. 15. Current module $I_{\mathrm{Wmax}}$ change under $\mathrm{C} 2$ phase $\mathrm{SC}$ to towers in span from $\mathrm{S} 2$ side: $1 \div 5$ th, 10 th, 15 th, 20th, 30th and 40 th for FOLW-...-18.7/93 and FOLW-...-12/94.

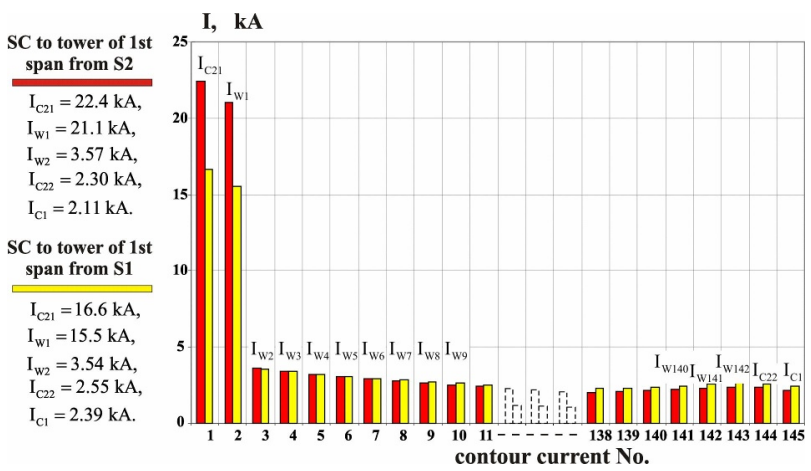

Fig. 16. Current module in LW and 220 OTL phases change under $\mathrm{C} 2$ phase SC to 1 st from S1 and S2 tower for FOLW-c$1-24(\mathrm{G} .652)-18.7 / 93$

$\mathrm{I}_{\mathrm{W} 1}$ greatest values under $\mathrm{SC}$ to $1^{\text {st }}$ from $\mathrm{S} 2$ span tower:

FOLW-...-18.7/93, $\mathrm{I}_{\mathrm{W} 1}=21.1 \mathrm{kA}$;

FOLW-...-14.7/61, $\mathrm{I}_{\mathrm{W} 1}=20.9 \mathrm{kA}$;

FOLW-...-13.1/54, $\mathrm{I}_{\mathrm{W} 1}=20.7 \mathrm{kA}$;

FOLW-...-12.0/94, $\mathrm{I}_{\mathrm{W} 1}=19.6 \mathrm{kA}$.

\section{SC currents as well as currents in LW of $220 \mathrm{kV}$ OTL operating in connected mode but without power transmission under simultanious C1 and C2 SC to first from S2 span tower}

Let's simultanious calculate $\mathrm{C} 1$ and $\mathrm{C} 2$ phases $\mathrm{SC}$ to the ground current as well as currents in LW induced by $\mathrm{MF}$ of SC to 1st span from S2 current of $220 \mathrm{kV}$ OTL operating in connected mode but without power trznsmission (Fig. 17).

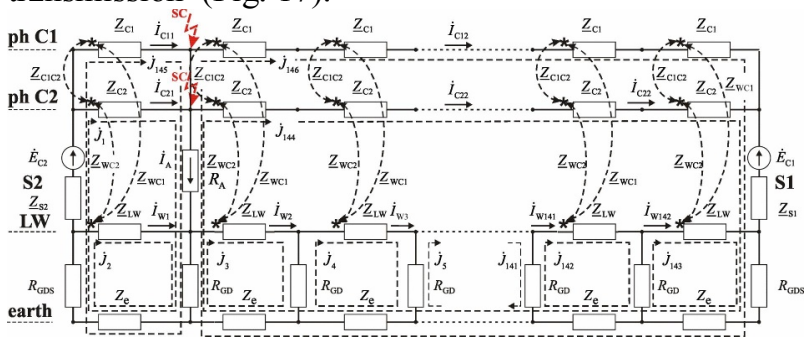

Fig. 17. The scheme of $\mathrm{C} 1$ and $\mathrm{C} 2$ phases $\mathrm{SC}$ to 1 st span current determination as well as currents in LW induced by MF of SC currents in $220 \mathrm{kV}$ OTL operating in connected mode but witout power transmission. 
Figure 18 shows the histograms of countour current modules in LW spans as well as currents in $\mathrm{C} 1$ and $\mathrm{C} 2$ under simultanious $\mathrm{C} 1$ and $\mathrm{C} 2$ phases $\mathrm{SC}$ to 1 st span tower for LW executed by FOLW-c-1-24(G.652)-18.7/93 and FOLW-c-1-48(G.652)-12/94, and figure 19 - executed by FOLW-c-1-16(G.652)-14.7/61 and FOLW-c-124(G.652)-13.1/54.

In case of simultanious $\mathrm{C} 1$ and $\mathrm{C} 2 \mathrm{SC}$ to tower of 1st span arc currents were: for FOLW-c-1-24(G.652)-18.7/93 $\boldsymbol{I}_{\mathrm{A}}=$ $25.01 \angle 43.4^{\circ} \mathrm{kA}$, for FOLW-c-1-48(G.652)-12/94 $\boldsymbol{I}_{\mathrm{A}}=$ $24.27 \angle 46.7^{\circ} \mathrm{kA}$, for FOLW-c-1-16(G.652)-14.7/61 $\boldsymbol{I}_{\mathrm{A}}=$ $24.92 \angle 44.1^{\circ} \mathrm{kA}$, and for FOLW-c-1-24(G.652)-13.1/54 $\boldsymbol{I}_{\mathrm{A}}$ $=24.78 \angle 44.6^{\circ} \mathrm{kA}$.

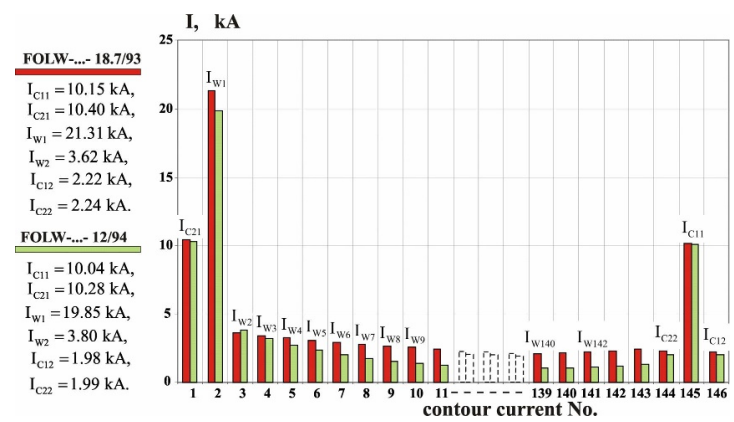

Fig. 18. Current module in LW and $220 \mathrm{kV}$ OTL phases changes under simultaneous $\mathrm{C} 1$ and $\mathrm{C} 2 \mathrm{SC}$ to the tower of $1^{\text {st }}$ span for FOLW-c-1-24(G.652)-18.7/93 and FOLW-c-1-48(G.652)-12/94

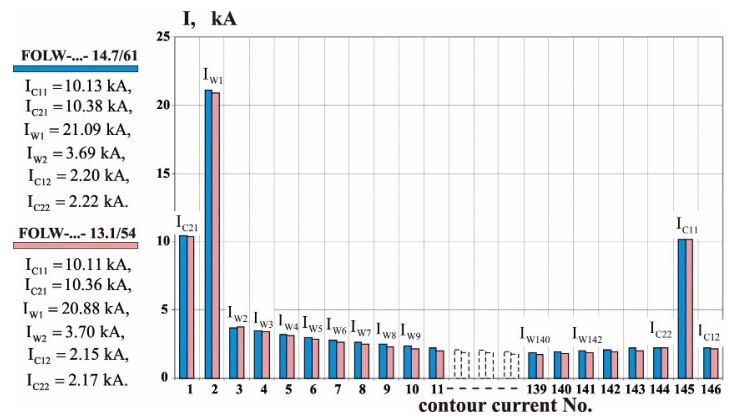

Fig. 19. Current module in LW and $220 \mathrm{kV}$ OTL phases changes under simultaneous $\mathrm{C} 1$ and $\mathrm{C} 2 \mathrm{SC}$ to the tower of $1^{\text {st }}$ span for FOLW-c-1-16(G.652)-14.7/61 and FOLW-c-1-24(G.652)$13.1 / 54$.

The greatest $I_{\mathrm{W} 1}$ current values under $\mathrm{C} 1$ and $\mathrm{C} 2 \mathrm{SC}$ to the tower of first from S2 span:

$$
\begin{aligned}
& \text { FOLW }-\ldots-18.7 / 93, I_{\mathrm{W} 1}=21.31 \mathrm{kA} ; \\
& \text { FOLW }-\ldots-14.7 / 61, I_{\mathrm{W} 1}=21.09 \mathrm{kA} ; \\
& \text { FOLW }-\ldots-13.1 / 54, I_{\mathrm{W} 1}=20.88 \mathrm{kA} ; \\
& \text { FOLW }-\ldots-12.0 / 94, I_{\mathrm{W} 1}=19.85 \mathrm{kA} .
\end{aligned}
$$

\section{Conclusion}

Currents created in LW have the greates values under its simultanious determination with currents of joint $\mathrm{C} 1$ and C2 SC to the first span from S 2 tower.
Maximal limit time of SC current shutdown ( $\left.t_{\text {Mlshutd }}\right)$ at $\mathrm{S} 2$ will find by FOLW thermal stability (ThS, $\left.\mathrm{kA}^{2} \mathrm{~s}\right)$ and recieved current $\left(I_{\mathrm{W} 1}\right)$ highest value in LW span: $t_{\mathrm{Mlshutd}}=\mathrm{ThS} / I_{\mathrm{W} 1}^{2}$. Maximal limit time of SC current shutdown $t_{\text {Mlshutd }}$ at $\mathrm{S} 2$ calculation results for analyzed FOLW brands are presented in table.

Table. Maximal limit time of SC current shutdown $\left(t_{\text {Mlshutd }}\right)$ at $\mathrm{S} 2$

\begin{tabular}{|c|c|c|c|c|c|}
\hline FOLW & $18.7 / 93$ & $14.7 / 61$ & $13.1 / 54$ & $12 / 94$ & $22.5 / 113$ \\
\hline $\begin{array}{c}\text { ThS, } \\
\mathrm{kA}^{2} \mathrm{~s}\end{array}$ & 350.2 & 132.7 & 78.7 & 31.2 & 969.9 \\
\hline$I_{\mathrm{W} 1}, \mathrm{kA}$ & 21.31 & 21.09 & 20.88 & 19.85 & 21.48 \\
\hline$t_{\mathrm{M} 1 \text { shutd }} \mathrm{s}$ & 0.771 & 0.298 & 0.164 & 0.079 & 2.102 \\
\hline
\end{tabular}

Analyzed FOLW brands have low maximal limit time of SC current and shutdown ( $\left.t_{\text {Mlshutd }}\right)$ (less than $\left.1 \mathrm{~s}\right)$. So FOLW-c-1-24(G.652)-22.5/113 with $22.5 \mathrm{~mm}$ diameter, $0.12 \mathrm{Ohm} / \mathrm{km}$ resisitivity and $\mathrm{ThS}=969.9 \mathrm{kA}^{2} \cdot \mathrm{s}$ thermal stability was chosen. This FOLW has under $\mathrm{C} 1$ and $\mathrm{C} 2$ phases $\mathrm{SC}$ to the $1 \mathrm{st}$ span from $\mathrm{S} 2$ tower $I_{\mathrm{W} 1}=21.48 \mathrm{kA}$, $I_{\mathrm{C} 11}=10.16 \mathrm{kA}, I_{\mathrm{C} 21}=10.42 \mathrm{kA}, I_{\mathrm{C} 12}=2.24 \mathrm{kA}, I_{\mathrm{C} 22}=$ $2.26 \mathrm{kA}$ and $t_{\text {Mlshutd }}=2.1 \mathrm{~s}$.

\section{References}

1. Zimin K.A., Rubtsova N.B., Riabchenko V.N., Tokarskskiy A.Yu. Currents in overhead transmission line lighting wire under single phase short circuit// Methodical question of large power systems reliability study: issue 69 . Reliability of developing power systems. In 2 books/ Book 2 / N.I. Voropai ed.- Irkutsk: ISEM RAS SD, 2018, 440 p. P. 247-256 . ISSN 2413-8665. (in Russian)

2. Kirill Zimin, Nina Rubtsova, Vladimir Riabchenko, Andrey Tokarskskiy. "Currents in the overhead transmission line lighting wire in case of single-phase short circuit»// E3S Web of Conferences 69, 02010 (2018) Green Energy and Smart Grids

2018 https://doi.org/10.1051/e3sconf/20186902010

3. M.V. Kostenko, L.S. Perelman, Yu.P. Shkarin Wave processes and electrical disturbances in multi-wire high-voltage lines. Energy. M., 272, (1973).

4. Kostenko M.V. Approximate formulas for resistance between lines modulus determining, taking into account the final earth conductivity. In Book. Protection of communication and alarm devices from high-voltage electrical installations influence. - M. Gosenergoizdat, 1959. - 335 p. (in Russian)

5. G.N. Tsitsikjan Electromagnetic compatibility in power industry. ELMOR. St-Petersburg, 184, (2007).(in Russian) 